Fogh, J. and Fogh, H. (1965). Proc, Soc exp. Biol. (N.Y.), 119, 233.

Grace, J. T., Horoszewicz, J. S., Stim, T. B., Mirand, E. A., and James, C. (1965). Cancer (Philad.), 18, 1369

Grist, N. R. (1966). Brit. med. '., 2, 1135.

Grist, N. R., and Fallon, R. J. (1964). Brit. med. 7., 2, 1263.

Grist, N. R., Ross, C. A. C., Bell, E. J., and Stott, E. J. (1966). Diagnostic Methods in Clinical Virology. Oxford.

Hayflick, L., and Koprowski, H. (1965). Nature (Lond.), 205, 713.

Heath, R. B., Fairley, G. H., and Malpas, J. S. (1964).' Brit. F. Haemat., 10, 365 .

Jensen, K. J., Senterfit, L. B., Scully, W. E., Conway, T. J., West, R. F., and Drummy, W. W. (1967). Amer. F. Epidem., 86, 419.

Kenny, G. E., and Grayston, J. T. (1965). F. Immunol., 95, 19.

Lazarus, H., Beckett, K. M. K., Cuppels, D., and Foley, G. E. (1967). 7. Bact., 94, 1797.

Leach, R. H., and Butler, M. (1966). 7. Bact., 91, 934
Macpherson, I., and Russell, W. (1966). Nature, (Lond.), 210, 1343.

Millian, S. J., and Spigland, I. (1966). Cancer (Philad.), 19, 1820.

Murphy, W. H., Ertel, I. J., Bullis, C., and Zarafonetis, C. J. D. (1967). Proc. Soc. exp. Biol. (N.Y.), 124, 366.

Murphy, W. H., Ertel, I. J., and Zarafonetis, C. J. D. (1965). Cancer (Philad.), 18, 1329.

Negroni, G. (1964). Brit. med. 7., 1, 927.

Paton, G. R., Jacobs, J. P., and Perkins, F. T. (1965). Nature (Lond.), 207, 43.

Suhs, R. H., and Feldman, H. A. (1966). Amer. F. Epidem., 83, 357.

Sutton, R. N. P. (1966). Brit. Med. F., 2, 1496 .

Sutton, R. N. P. (1966). Brit. Med. H. W, 1496. C and Chanock, R. M (1966a). F. Hyg. (Lond.), 64, 91.

Taylor-Robinson, D., Shirai, A., Soběslavský, O., and Chanock, R. M. (1966b). Amer. F. Epidem., 84, 301.

Tobin, B. M., and Jones, D. M. (1967). Brit. med. F., 1, 758.

\title{
Studies in the Epidemiology of Tinea Pedis. IX: Tinea Pedis and Erythrasma in New Patients at a Chiropody Clinic
}

\author{
MARY P. ENGLISH,* M.SC. ; J. TURVEY, $\dagger$ M.CH.S., s.R.CH.
}

\begin{abstract}
Summary : The feet of 259 new patients at a chiropody $\checkmark$ clinic were examined for tinea pedis, onychomycosis, and erythrasma : $23 \%$ of men and $4 \%$ of women were infected by dermatophytes, and the nails of seven males were infected by non-dermatophytes. Of 200 patients examined under Wood's light $37 \%$ showed the coral-red fluorescence of erythrasma.

Of the 259 patients, $9.7 \%$ were infected by Trichophyton interdigitale, $2.7 \%$ by $T$. rubrum, and $1.5 \%$ by Epidermophyton floccosum. Reasons are given, based on the method of selection of the patients, for supposing that $T$. interdigitale is still the dominant cause of tinea pedis in the population at large, despite figures from dermatological clinics suggesting the dominance of $T$. rubrum. The high incidence of infection in males compared with females corresponds with similar findings in schoolchildren.
\end{abstract}

\section{Introduction}

The great majority of cases of tinea pedis are mild, and are treated by the patient himself or by the general practitioner. Yet almost all published figures for its incidence, and for the incidence of the fungi causing it, have been based on persons attending skin clinics who have the disease sufficiently severely to have been referred to these specialist centres. All figures so obtained are bound to be biased towards a high total incidence and towards the species of fungus causing the most severe, widespread, and recalcitrant lesions. The nearest approach to studies of the ordinary population have been those carried out among children in day schools; for instance, in this country, by English and Gibson (1959). Nothing is known of the incidence of the disease, or of the fungi causing it, in the adult population at large, mainly because of the difficulty of accurate sampling and the magnitude of the task.

It had been observed by one of us (J. T.) that very few people attending a chiropodist come with an initial complaint of tinea pedis. Such people, therefore, while admittedly not constituting a random sample of the adult population, approach such a sample closely enough to provide a practical substitute for an otherwise impracticable undertaking. It was chiefly for this reason that the present survey of new patients attending a chiropody clinic was begun.

* Mycologist, General Hospital, Bristol 1

+ Senior Lecturer, Chelsea School of Chiropody, London N.W.8.

\section{Subjects}

The subjects comprised new patients seen by one of us (J. T.) at a weekly clinic held only during term-time at the Chelsea School of Chiropody. Many more women than men attended the clinic; therefore, to obtain the required numbers of each sex, both men and women were included from 8 October 1964 to 29 April 1965, and men only were examined from 8 October 1965 to 10 February 1966 and from 27 October 1966 to 18 May 1967. Though men were examined over a much longer period than women this is unlikely to have distorted our results, as they were always seen at the same times of year.

After our survey was complete Koch (1967) pointed out that in Erfurt (Germany) chiropody clinics themselves were the most prolific source of cross-infection with tinea pedis of the various sports and cosmetic establishments examined by him. No such investigation has been carried out in British chiropody clinics, but Koch's findings do not invalidate our results, as all our subjects were new patients.

Scrapings were taken by J. T. from all scaling, erythematous, macerated, pustular, or cracked iesions of the foot, and clippings were obtained from any dystrophied or discoloured toe-nails, unless clearly of non-mycotic origin. In lesion-free patients scrapings were taken from between the fourth and fifth toes. As all patients with lesions elsewhere than in the toe-wébs also had them on the latter site, scrapings were, in fact, obtained from the toe-webs of every patient. It has been pointed out by numerous workers-for example, Gentles and Holmes (1957)-that the incidence of tinea-like lesions on the feet far exceeds the incidence of true fungal infection. This was also true in this survey, but the fact is so well known that figures for the total incidence of lesions are omitted.

All clinical material was posted to Bristol for laboratory examination, which was carried out by M.P.E.

All the women and the first 102 men were screened for interdigital erythrasma by examination of their toe-webs for coralred fluorescence under Wood's light.

Relevant particulars of each patient were filled in on a questionary prepared in such a way that the replies could be used for punched card analysis without further coding.

\section{Laboratory Methods}

The laboratory methods used for fungi were the standard methods of microscopy and culture used previously in this 
series (English, Wethered, and Duncan, 1967). When nondermatophyte infections of nails were suspected, Actidione (cycloheximide) was omitted from the culture medium. Initial attempts to culture Corynebacterium minutissimum, the causal organism of erythrasma, by the method of Sarkany, Taplin, and Blank (1961) were unsuccessful and were abandoned, the diagnosis being made exclusively on fluorescence under Wood's light.

\section{Results}

The 259 patients seen comprised 98 women and 161 men. The inclusion of more men than women was deliberate, and the reason is given below.

\section{Comparison of Sample with General Population}

Compared with the population as a whole Table I shows that our sample was weighted towards the higher age groups, and Table II that the numbers in the Registrar General's social class III were disproportionately low. It is known that since 1961 , the latest date for which figures of social class are available, the proportion of the population in classes IV and V has fallen considerably, so that these classes are even more overrepresented in our sample than appears from Table II. These discrepancies must be borne in mind when assessing our results.

TABLE I.-Comparison of Age Distribution of Patients With that of the Population of England and Wales as Reported in Registrar General's Return for First Quarter of 1966

\begin{tabular}{|c|c|c|c|}
\hline \multirow{2}{*}{ Age Group } & \multicolumn{2}{|c|}{ Chelsea Patients } & \multirow{2}{*}{$\begin{array}{c}\text { Quarterly } \\
\text { Return } 1966 \\
(\%)\end{array}$} \\
\hline & No. & $\%$ & \\
\hline $\begin{array}{l}20-29 \text { years } \\
30-39 " \prime \\
40-49 " \\
50-59 " \\
60-69 " \\
70+\quad "\end{array}$ & $\begin{array}{l}27 \\
29 \\
30 \\
61 \\
64 \\
48\end{array}$ & $\begin{array}{l}10 \cdot 4 \\
11 \cdot 2 \\
11 \cdot 6 \\
23 \cdot 6 \\
24 \cdot 7 \\
18 \cdot 5\end{array}$ & $\begin{array}{l}18 \cdot 6 \\
17 \cdot 9 \\
18 \cdot 9 \\
18 \cdot 8 \\
14 \cdot 5 \\
11 \cdot 2\end{array}$ \\
\hline Total & 259 & & \\
\hline
\end{tabular}

TABLE II.-Comparison of Distribution of Social Class of Patients With that of the 1961 Census*

\begin{tabular}{|c|c|c|c|}
\hline \multirow{2}{*}{$\begin{array}{l}\text { Registrar } \\
\text { General's } \\
\text { Social Class }\end{array}$} & \multicolumn{2}{|c|}{ Chelsea (Males) } & \multirow{2}{*}{1961 Census } \\
\hline & No. & $\%$ & \\
\hline $\begin{array}{l}\text { I and II } \\
\text { III } \\
\text { IV and V }\end{array}$ & $\begin{array}{l}42 \\
66 \\
53\end{array}$ & $\begin{array}{l}26 \cdot 1 \\
41 \cdot 0 \\
32 \cdot 9\end{array}$ & $\begin{array}{l}20 \cdot 8 \\
51 \cdot 3 \\
27 \cdot 9\end{array}$ \\
\hline Total & 161 & & \\
\hline
\end{tabular}

* Obtained from $10 \%$ household sample for England and Wales (Kellmer Pringle, Butler, and Davie, 1966).

Of the 259 patients, the primary complaint of 11 was "athlete's foot," while in two others this condition was an additional complaint to that primarily causing the visit. Of these $13(5 \%)$ only $6(2.3 \%)$ were found to have a fungal infection on laboratory examination, two having Trichophyton rubrum and four $T$. interdigitale. While, therefore, there was some selection for patients with tinea pedis, this was small.

\section{Incidence of Infection}

Table III shows the incidence of the various types of infection. Of the results, three are especially striking: firstly, the very much higher rate of fungal infection in males than in females, whether or not the non-dermatophytes are included ( $P<0.001$ for all fungi and for dermatophytes only) ; secondly, the great preponderance of $T$. interdigitale over $T$. rubrum infections in the whole group $(P<0.01)$; and, thirdly, the very high incidence of erythrasma in both sexes. One patient with normal interdigital skin showed coral-red fluorescence under Wood's light.
TABLE III.-Incidence of Fungal Infections and Erythrasma

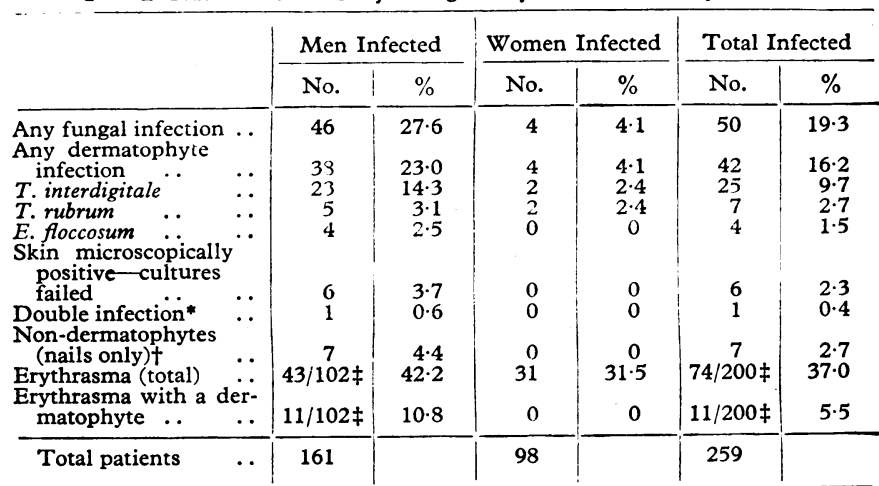

* Skin and nail microscopically positive: cultures failed from both, but spores of non-dermatophyte present in nail.

+ One case each of Aspergillus unguis, A. sydowi, A. terreus, A. versicolor, three

$\ddagger$ Only 102 and 200 patients respectively examined for erythrasma.

TABLE IV.-Relation of Nail Infections to Age

\begin{tabular}{|c|c|c|c|c|}
\hline \multirow{2}{*}{\multicolumn{2}{|c|}{ Age Group }} & \multirow{2}{*}{ Total Patients } & \multicolumn{2}{|c|}{ Total Nail Infections } \\
\hline & & & No. & $\%$ \\
\hline \multirow[t]{2}{*}{$\begin{array}{l}20-39 \text { years } \\
40-59 \text { ", } \\
60+\quad \text { " }\end{array}$} & $\begin{array}{l}\ddot{*} \\
\cdots\end{array}$ & $\begin{array}{r}56 \\
91 \\
112\end{array}$ & $\begin{array}{r}4 \\
5 \\
14\end{array}$ & $\begin{array}{r}7 \cdot 2 \\
5 \cdot 5 \\
12 \cdot 5\end{array}$ \\
\hline & & 259 & 23 & 8.9 \\
\hline
\end{tabular}

The incidence of mixed fungal infections was very low, as would be expected in a group of persons with no social interconnexions (English et al., 1967), and that of fungal infection combined with erythrasma does not suggest any special relation between these conditions $(0.5<\mathrm{P}<0.7)$. In $8.9 \%$ of patients (including those with non-dermatophytes) nail infections were present. Table IV suggests that this rather high incidence is due to the disproportionate number of elderly people in the survey (Walshe and English, 1966 ; English et al., 1967).

\section{Epidemiology}

When the survey was undertaken it was hoped that some epidemiological data could be obtained in addition to that on incidence, and the questionary was planned to this end. It was ascertained that the sexual difference in the incidence of tinea pedis was not due to any statistically significant differences in the sample with respect to the age range of the patients, their social status, the numbers who had ever lived in a residential community (other than H.M. Forces) or the numbers who had bathrooms in their houses (almost all had). Contrary to general belief there was also no significant difference between the numbers of each sex with crowded toes $37 \%$ males and $32 \%$ females). However, $29 \%$ of men had used swimming-baths frequently at some stage in their lives compared with $16 \%$ of women $(P<0.01)$, and $65 \%$ of men had been in the Forces compared with $3 \%$ of women $(\mathrm{P}<0.001)$, and it was felt that these factors might have contributed to the difference in incidence.

Because of the very low incidence of tinea pedis in women it was decided to make further epidemiological comparisons on men only rather than on total patients, and it was for this reason that more men than women were investigated. However, contrary to results obtained in other studies of this series, and by other workers, no statistically significant difference in age, social class, attendance at swimming-baths, community living, service in the Forces, or crowding of toes could be established between men with tinea pedis and those without. It is presumed that this inconclusive result is attributable to the small number of men (161) investigated. 
An attempt was made to relate the incidence of erythrasma in men and women combined (200 patients in all) to the above factors, but again there was no significant relation.

\section{Discussion}

Despite the fact that our sample was not completely typical of the population at large, and that the numbers examined were small, this survey comes nearer than any other published work to giving a picture of the incidence of tinea pedis in the adult British public. It is clear that, in contrast to experience with the highly selected populations of skin clinics in Britain and many other countries, and in accordance with the results of English and Gibson (1959) with schoolchildren, and of Walshe and English (1966) with onychomycosis in a consecutive series of skin clinic patients, $T$. interdigitale is still the most common cause of tinea pedis in the population. It is not disputed that the incidence of $T$. rubrum in this country is, in fact, rising rapidly. For instance, in dermatological clinics in the South-west of England in 1955 the number of cases of $T$. rubrum infection was equal to that of $T$. interdigitale, but in 1967 there were 2.5 times as many cases of the former as of the latter. But despite this it will probably be many years before the incidence of $T$. rubrum overtakes that of $T$. interdigitale in the population at large. If this is so in Britain it is probably also the case in many other countries which claim T. rubrum as the dominant cause of tinea pedis on the basis of skin clinic statistics. It would be interesting if those countries could carry out similar surveys to ours, but preferably on a larger scale.

This survey shows that the sex difference in the incidence of tinea pedis noted by English and Gibson (1959) for day-school children continues into adult life. Unfortunately, owing to the smallness of the sample, no further information was gained on why this should be so-that is, whether it is due to some innate physiological resistance in the female or to one or more of the many differences in the habits and ways of life of the sexes.

It was unfortunate, in view of Koch's (1967) investigations into the incidence of tinea pedis in chiropodists' patients, that in our series no record was kept of patients' previous attendance at other chiropody clinics. However, in view of the large preponderance of women attending these clinics and the low incidence of tinea pedis among them it would seem probable that, in this country, such establishments do not contribute greatly to the spread of the disease.

If fluorescence under Wood's light is valid as the sole diagnostic criterion for erythrasma, the incidence of the condition in the toe-webs of our patients $(37 \%)$ was higher even than that recorded by Sarkany, Taplin, and Blank (1962) in their pioneer survey in a London skin clinic $(25 \%)$. But our failure to isolate $C$. minutissimum by the method of these authors, and the occurrence of fluorescence in a lesion-free patientwhich has also been reported by Ayres and Mihan (1968)add support to the contention of Ayres and Mihan that further investigation into the cause or causes of coral-red fluorescence could be rewarding.

We are indebted to Miss E. H. L. Duncan, lecturer in medical statistics at Bristol University, for her help in planning the survey and interpreting the results. We are also grateful to Mr. T. Morgan and Miss C. Walker for laboratory assistance.

\section{REFERENCES}

Ayres, S., and Mihan, R. (1968). Arch. Derm., 97, 173.

Anres, S., and Mrit. med. 7. 1, 1442

English, M. P., Wethered, R. R., and Duncan, E. H. L. (1967). Brit. med. Э., 3, 136 .

Gentles, J. C., and Holmes, J. G. (1957). Brit. F. industr. Med., 14, 22.

Kellmer Pringle, M. L., Butler, N. R., and Davie, R. (1966). 11.000 Seven-Year-Olds, p. 8. London.

Koch, H. A. (1967). Mykosen, 10, 203.

Sarkany, I., Taplin, D., and Blank, H. (1961). F. invest. Derm., 37, 283.

Sarkany, I., Taplin, D., and Blank, H. (1962). Arch. Derm., 85, 578.

Walshe, M. M., and English, M. P. (1966). Brit. F. Derm., 78, 198.

\section{Medical Memoranda}

\section{Primary Hyperparathyroidism Presenting as Spinal Cord Compression}

Brit. med. F., 1968, 4, 230-231

Primary hyperparathyroidism may present clinically in a variety of guises. Renal calculi are common, as are symptoms due to hypercalcaemia, such as drowsiness, anorexia, abdominal pain, constipation, nausea, and vomiting. Bone disease may manifest itself with bone pain, fractures, or swelling of the bones due to the so-called "brown tumours." The following case illustrates an unusual mode of presentation of primary hyperparathyroidism, the symptoms being caused by a giant-cell tumour in an unusual site.

\section{CASE REPORT}

The patient, a woman aged 58, was admitted to hospital on 19 February 1968 with a nine-weeks history of back pain, weakness of the legs for one week, and urinary retention for 18 hours. She had enjoyed good health until nine weeks before admission, when she began to experience a persistent knife-like pain in her left shoulder and a dull ache in her back, mostly on the left side. Four weeks later the pain became localized to the lower part of the thoracic spine and left loin. It was stabbing in character with no radiation, accentuated by coughing and movement, and eased by bed rest. During her last week at home she had noticed weakness in her legs, and for the five days before admission had been unable to walk.

On admission she was found to have had retention of urine for 18 hours; there were no sensory symptoms and no weakness in the upper limbs. Inquiry revealed a six-weeks history of anorexia and increasing constipation, but no nausea or vomiting. On examination a swelling was found in the inferior aspect of the left lobe of the thyroid gland. No bony tenderness was present, but the lumbar muscles were very tender to palpation. Neck flexion accentuated the back pain. The lower limbs showed marked muscle-wasting but no fasciculation. Tone was flaccid, with reduced power in all muscle groups. Tendon reflexes were brisk but symmetrical, and there was no clonus. Both plantar reflexes were extensor.

On investigation her E.S.R. was $27 \mathrm{~mm}$. in one hour (Westergren), haemoglobin 13.8 g. $/ 100$ ml., M.C.H.C. $33 \%$, and white 